For Organic Electronics

\title{
Inkjet-Printed Copper Electrodes using Photonic Sintering and their Application to Organic Thin-Film Transistors
}

\author{
Shohei Norita, ${ }^{a}$ Daisuke Kumaki, ${ }^{\text {abb }}$ Yu Kobayashi, ${ }^{a}$ Tsubasa Sato, ${ }^{a}$ Kenjiro Fukuda,,${ }^{a, b}$, \\ and Shizuo Tokito ${ }^{\mathrm{a}, \mathrm{b}}$ \\ ${ }^{a}$ Graduate School of Science and Engineering, Yamagata University, 4-3-16, Jonan, Yonezawa, \\ 992-8510 Yamagata, Japan \\ ${ }^{b}$ Research Center for Organic Electronics (ROEL), Yamagata University, 4-3-16, Jonan, Yonezawa, \\ 992-8510 Yamagata, Japan \\ Corresponding author: Daisuke Kumaki \\ E-mail: d_kumaki@yz.yamagata-u.ac.jp
}

\section{Keywords:}

Organic thin-film transistor

Copper nanoparticle ink

Inkjet-printing

Photonic sintering 


\begin{abstract}
We report on copper $(\mathrm{Cu})$ electrodes fabricated with inkjet-printed nanoparticle inks that are photonic sintered on a polymer dielectric layer and their application to source and drain electrodes in organic thin-film transistor (TFT). By using photonic sintering with a radiant energy density of 9 $\mathrm{J} / \mathrm{cm}^{2}$, printed $\mathrm{Cu}$ nanoparticle layers on a glass substrate showed very low electrical resistivity levels of $7 \mu \Omega \cdot \mathrm{cm}$. By optimizing the sintering conditions on polymer dielectric, the pentacene-based TFT using these printed $\mathrm{Cu}$ electrodes showed good mobility levels of 0.13 $\mathrm{cm}^{2} /$ Vs and high on/off current ratios of about $10^{6}$. In addition, we revealed that the crystal grain growth of pentacene near the printed $\mathrm{Cu}$ electrodes was inhibited by the thermal damage of polymer underlayer due to the high radiant energy density of the intense light.
\end{abstract}




\section{Introduction}

In recent years, printing technology has attracted considerable attention in research and development because it can be used to fabricate low-cost and large-area electronic devices, using printing technology, which expected to be used in the manufacturing process for flexible displays devices [1-3], printed sensors [4-6], memory devices [7] and radio frequency identification (RFID) tags $[8,9]$. Although the development of semiconductor inks is very important to realize a high performance circuit, the conductive inks are also the key material for fabricating fully printed thin-film transistor (TFT). Generally, silver (Ag) pastes or Ag nanoparticle inks is widely used because these materials are can easily obtain high levels of conductivity with low sintering temperatures below $150{ }^{\circ} \mathrm{C}$, which is very important characteristic to use on the plastic substrate. In addition, sintering temperatures for Ag nanoparticle inks have drastically decreased due to the recent developments in reduction in nanoparticle sizes $[10,11]$.

Alternatively, copper $(\mathrm{Cu})$ nanoparticle inks have recently attracted attention as a new class of conductive ink, since the $\mathrm{Cu}$ is a low cost metal and has higher resistance to the electromigration compared to $\mathrm{Ag}$ [12]. However, $\mathrm{Cu}$ nanoparticle inks generally require high sintering temperatures above $300^{\circ} \mathrm{C}$ to obtain high conductivities $[13,14]$. To address this problem, photonic sintering using intense pulsed light with millisecond exposure times and a wide range of wavelengths has been reported as the most useful sintering method for the $\mathrm{Cu}$ nanoparticles [15-18]. A $\mathrm{Cu}$ nanoparticle layer can be converted to a highly conductive layer due to instantaneous heat generation within the layer accompanied by absorption of the intense pulsed light. Photonic 
sintering can also selectively heat $\mathrm{Cu}$ nanoparticle layers, therefore making it possible to significantly suppress the temperature rise in the underlying substrate material.

Some research groups have reported improvements in layer conductivity or the reduction of sintering temperature for $\mathrm{Cu}$ nanoparticles, however they have focused on the application to interconnect technologies on flexible polymer film at low temperatures [15-18]. There have been few reports on the application of the printed $\mathrm{Cu}$ electrodes to TFT $[13,14]$. Furthermore, the use of photonic sintering for $\mathrm{Cu}$ nanoparticle inks in TFT fabrication has not been investigated to date. In organic TFT, interface control for the source and drain (S/D) electrodes, such as optimization of the physical contact and energy level to the organic semiconductor layer, is the key to achieving high electrical performance. Therefore, it is very important to investigate the use of printed $\mathrm{Cu}$ electrodes in organic TFT, which is fabricated with $\mathrm{Cu}$ nanoparticle inks that are photonic sintered.

In this paper, we report on the printed $\mathrm{Cu}$ electrodes fabricated by inkjet printing using $\mathrm{Cu}$ nanoparticle ink and photonic sintering, and their application to the organic TFTs. By using photonic sintering, the printed $\mathrm{Cu}$ nanoparticle layers exhibited low electrical resistivities. We have investigated the optimized condition of the photonic sintering for $\mathrm{Cu}$ nanoparticles to reduce the thermal damage to the underlying polymer dielectric layer. By controlling the light intensity, large deformations in polymer layer resulting from thermal damage by the sintering process were drastically reduced. An organic TFT using pentacene as the organic semiconductor was fabricated and exhibited good electrical performance. 


\section{Experimental}

We used $\mathrm{Cu}$ nanoparticle ink purchased from Ishihara Chemicals $\mathrm{Co}$. $(\mathrm{Cu}-02)$ for the printed electrodes, which consisted of $\mathrm{Cu}$ nanoparticles with average sizes of $70 \mathrm{~nm}$ dispersed in organic solvents with a $\mathrm{Cu}$ concentration of approximately $50 \mathrm{wt} \%$. The $\mathrm{Cu}$ nanoparticle ink was patterned by using an inkjet printer (DMP-2831, Fujifilm Dimatix). In order to obtain a high conductivity, the patterned $\mathrm{Cu}$ nanoparticle layers were sintered using a Xenon (Xe) flash lamp, which had a broad emission spectrum ranging from 350 to $1100 \mathrm{~nm}$. Fig. 1 shows a schematic image of the light irradiation system (ES-UX03, Sugawara Laboratories Inc.). To achieve uniform irradiation of the light with high intensity over large areas, a light source unit was used that consisted of nine Xe lamps and a dome mirror. The light intensity of the irradiation system can be controlled by varying the charging voltage, the duration of light pulse and the distance between the top of sample and the bottom of Xe lamp unit.

Fig. 2 shows the organic TFT structure (bottom-gate and bottom-contact configuration) as fabricated and tested for this report. First, an aluminum (Al) layer was vacuum-deposited onto a glass substrate through a shadow mask with a thickness of $50 \mathrm{~nm}$ to form the gate electrode. A benzocyclobutene (BCB) polymer (CYCLOTENE ${ }^{\mathrm{TM}}$ 3022-35, Dow Chemical) [19] layer (600 nm thickness) was then spin-coated onto the substrate and annealed at $300{ }^{\circ} \mathrm{C}$ for 1 hour. The $\mathrm{Cu}$ nanoparticle ink was patterned with the inkjet printer to form the S/D electrodes on the underlying polymer dielectric layer. After drying at $50{ }^{\circ} \mathrm{C}$ for $5 \mathrm{~min}$, the patterned $\mathrm{Cu}$ nanoparticle layer was sintered in air with the Xe flash unit with a radiant energy density of $4.4 \mathrm{~J} / \mathrm{cm}^{2}$ and pulse duration of 
$0.8 \mathrm{~ms}$ (FWHM). Next, the substrate was immersed in a pentafluorobenzenethiol (PFBT) solution (30 mM PFBT dissolved in IPA) for 5 min to treat the surfaces of the S/D electrodes [20]. Finally, a pentacene layer with a thickness of $50 \mathrm{~nm}$ was vacuum-deposited onto the $\mathrm{S} / \mathrm{D}$ electrodes.

The surface morphology of $\mathrm{Cu}$ electrodes was observed using a field-emission SEM (FE-SEM) (JSM7600FA, JEOL Ltd.) and an atomic force microscope (AFM) (Nanoscope V, Bruker Instruments). The electrical characteristics for the organic TFT were measured using a semiconductor parameter analyzer (4200-SCS, Keithley Instruments). The work function for the electrodes was estimated using photoelectron spectroscopy in air (AC-3, Riken Keiki).

\section{Results and discussion}

Fig. 3(a) shows the resistivity of $\mathrm{Cu}$ electrodes as a function of the radiant energy. Here, a single flash light was irradiated to the inkjet-printed $\mathrm{Cu}$ nanoparticle layer on glass substrate, such that the variation in light intensity was less than $10 \%$ over an area of $4 \mathrm{~cm} \mathrm{x} 4 \mathrm{~cm}$, providing very good uniformity in the radiant energy across the sample substrate $(2 \mathrm{~cm} \times 2.5 \mathrm{~cm})$. The resulting thickness of $\mathrm{Cu}$ nanoparticle layer was about $300 \mathrm{~nm}$. The resistivities decreased with increases the radiant energy. Low resistivities of less than $10 \mu \Omega \cdot \mathrm{cm}$, which are the same order as the resistivity for bulk $\mathrm{Cu}$, was achieved by irradiating the samples with more than $5 \mathrm{~J} / \mathrm{cm}^{2}$ of radiant energy. The lowest resistivity of $7 \mu \Omega \cdot \mathrm{cm}$ was achieved with a light intensity corresponding to an energy density of $9 \mathrm{~J} / \mathrm{cm}^{2}$. Fig. $3 \mathrm{~b}$ and 3c show SEM images of the surface of $\mathrm{Cu}$ nanoparticle layer before and after flash lamp irradiation with an energy density of $5.9 \mathrm{~J} / \mathrm{cm}^{2}$, which resulted in fused $\mathrm{Cu}$ 
nanoparticles. These results indicate that the $\mathrm{Cu}$ nanoparticles were sintered instantaneously by the generated thermal energy resulting from absorption of radiant energy from the high intensity Xe flash lamps.

To employ these inkjet-printed $\mathrm{Cu}$ layers to the S/D electrodes in organic TFTs, the sintering conditions for the $\mathrm{Cu}$ nanoparticle layer on the polymer dielectric were optimized. The $\mathrm{Cu}$ nanoparticle layer was patterned by inkjet printing on a BCB polymer layer with a line width of 200 $\mu \mathrm{m}$. Fig. 4 shows the cross-sectional profiles of the $\mathrm{Cu}$ electrodes on $\mathrm{BCB}$ polymer layer after photonic sintering with radiant energy densities of (a) $4.4 \mathrm{~J} / \mathrm{cm}^{2}$ and (b) $5.9 \mathrm{~J} / \mathrm{cm}^{2}$, respectively. No damage was observed in the $\mathrm{Cu}$ electrode or the $\mathrm{BCB}$ polymer underlayer at a radiant energy density of $4.4 \mathrm{~J} / \mathrm{cm}^{2}$. In contrast, large deformations in $\mathrm{Cu}$ electrode layer and $\mathrm{BCB}$ polymer underlayer were observed at a radiant energy density of $5.9 \mathrm{~J} / \mathrm{cm}^{2}$, as shown in Fig. 4b. In this case, the resistivity is difficult to estimate because of the discontinuities in the $\mathrm{Cu}$ electrode layer due to deformation of polymer underlayer. The primary reason for the large amount of deformation after photonic irradiation at the higher energy is attributed to thermal damage, which is from the residual energy from the $\mathrm{Cu}$ electrode conducted as heat to the $\mathrm{BCB}$ polymer during irradiation. This degree of deformation was not observed on a BCB polymer layer directly irradiated by the Xe flash lamp. From these results, it is considered that the polymer insulator with higher glass transition temperature and higher melting point is suitable for the suppression of the thermal damage. The resistivity of the $\mathrm{Cu}$ electrode shown in Fig. 4a was $14 \mu \Omega \cdot \mathrm{cm}$, which is comparable to that on a bare glass substrate with same irradiation conditions and is sufficient for use as the S/D electrodes 
in organic TFTs. In addition, this resistivity using photonic sintering was lower than that of thermal sintering at $350^{\circ} \mathrm{C}$ on glass substrate $(18 \mu \Omega \cdot \mathrm{cm})$. Therefore, we concluded that a radiant energy density of $4.4 \mathrm{~J} / \mathrm{cm}^{2}$ is optimal photonic sintering to printed $\mathrm{Cu}$ electrodes when the $\mathrm{BCB}$ polymer underlayer is used as the gate dielectric.

Next, we employed the inkjet-printed $\mathrm{Cu}$ electrodes to S/D electrodes in an organic TFT with channel length (L) and width (W) were 50 and $1000 \mu \mathrm{m}$, respectively. Fig. 5a shows the transfer characteristics of the pentacene-based TFT with the printed $\mathrm{Cu}$ electrodes treated with and without a PFBT solution. The solid and dashed lines in Fig. 5a correspond to drain current (IDS) and gate current (IGs). Since no leakage current was observed in IGs, deformation in the BCB layer was considered negligible. The organic TFT with untreated $\mathrm{Cu}$ electrodes exhibited a poor carrier mobility of $0.03 \mathrm{~cm}^{2} / \mathrm{Vs}$. However, the organic TFT with treated $\mathrm{Cu}$ electrodes showed an increase in on-current and a higher mobility of $0.13 \mathrm{~cm}^{2} / \mathrm{Vs}$. The threshold voltage $\left(\mathrm{V}_{\text {th }}\right)$ and on/off current ratio were $-7.8 \mathrm{~V}$ and $10^{6}$, respectively. An increase in the work function of the $\mathrm{Cu}$ electrodes from $4.9 \mathrm{eV}$ to $6.1 \mathrm{eV}$ was confirmed using the PFBT treatment, as shown in Fig. 6. These results indicate that improvements in electrical performance can be attributed to a lowering of the energy barrier between the $\mathrm{Cu}$ electrode and semiconducting pentacene layer. We estimated the contact resistance $\left(\mathrm{R}_{\mathrm{C}}\right)$ extracted using the transfer line method (TLM) [21]. Fig. 7a shows the total resistance in the channel as a function of channel length. As shown in Fig. 7b, the contact resistance of the printed $\mathrm{Cu}$ electrode with PFBT treatment was $0.31 \mathrm{M} \Omega \mathrm{cm}$ at $\mathrm{V}_{\mathrm{GS}}$ of $-40 \mathrm{~V}$. However, this value is one order of magnitude higher than that of the previously reported pentacene TFT with 
printed electrode [10].

In order to better understand the reasons for the high contact resistance, we observed the structure of the $\mathrm{BCB}$ polymer underlayer and the pentacene layer near the printed $\mathrm{Cu}$ electrodes. Fig. 8 shows AFM images taken at the edge of the $\mathrm{Cu}$ electrode (a) before photonic sintering, (b) after pentacene deposition on the surface without photonic sintering, (c) after photonic sintering, and (d) after pentacene deposition on the photonic sintered $\mathrm{Cu}$ electrode. To clearly observe the shape of the electrode edge, the images were processed using an error signal mode calculated from the derivative value of the height. Before photonic sintering a distinct and uniform printed $\mathrm{Cu}$ electrode edge and a smooth BCB polymer underlayer surface were observed, as shown in Fig. 8a. The roughness $\left(\mathrm{R}_{\mathrm{q}}\right)$ on $\mathrm{BCB}$ polymer underlayer was about $0.3 \mathrm{~nm}$. After pentacene deposition on the $\mathrm{BCB}$ layer surface and before photonic sintering, grain sizes with consistent quality were observed in pentacene layer. However, after photonic sintering, an increase in the surface roughness of the BCB polymer underlayer was observed near the $\mathrm{Cu}$ electrode, as shown in Fig. 8c. The rough surface was largely due to heat conduction from the $\mathrm{Cu}$ electrode to the $\mathrm{BCB}$ polymer during or after the photonic sintering process, because no damage to the BCB polymer was observed at distances further from the $\mathrm{Cu}$ electrode. In fact, the areas that exhibited roughness were less than $1 \mu \mathrm{m}$ from the $\mathrm{Cu}$ electrode and $\mathrm{R}_{\mathrm{q}}$ had increased from 0.2 to $1.6 \mathrm{~nm}$ due to thermal damage. As shown in Fig. 8d, the grain sizes of pentacene on the damaged BCB polymer layer were also relatively small, compared with that on the $\mathrm{BCB}$ polymer at distances further from the $\mathrm{Cu}$ electrode. These results indicate that the contact resistance of pentacene TFT was increased as a result of thermal damage to 
the $\mathrm{BCB}$ polymer layer near the edges of the electrode, because both the grain size of semiconducting pentacene layer and the roughness of the BCB polymer underlayer influence charge transport $[22,23]$. Therefore, thermal damage to the polymer underlayer must be further suppressed to maximize transistor performance.

\section{Conclusions}

We have demonstrated a high-speed photonic sintering process for $\mathrm{Cu}$ nanoparticle inks to create low-resistivity conductive electrode layers. A minimum resistivity of $7 \mu \Omega \cdot \mathrm{cm}$ was achieved on a glass substrate using light intensity corresponding to a radiant energy density of $9 \mathrm{~J} / \mathrm{cm}^{2}$. In order to use the printed $\mathrm{Cu}$ electrodes for the organic TFTs, the sintering conditions and their effect in the underlying polymer dielectric layer were optimized. By controlling the radiant energy, conductive layers with very low resistivity of $14 \mu \Omega \cdot \mathrm{cm}$ were achieved on polymer dielectric layers without thermal deformation or damage. An organic TFT with inkjet-printed and photonic sintered $\mathrm{Cu}$ S/D electrodes on a polymer dielectric underlayer was fabricated. The pentacene TFT showed a good carrier mobility of $0.13 \mathrm{~cm}^{2} / \mathrm{Vs}$ and an on/off current ratio of $10^{6}$.

\section{Acknowledgements}

This study was supported by the Japan Science and Technology Agency (JST) and a New Energy and Industrial Technology Development Organization (NEDO). 


\section{References}

[1] M. Noda, N. Kobayashi, M. Katsuhara, A. Yumoto, S. Ushikura, R. Yasuda, N. Hirai, G. Yukawa, I. Yagi, K. Nomoto, and T. Urabe, J. Soc. Inf. Display 19 (2011) 316.

[2] K. Suzuki, K. Yutani, M. Nakashima, A. Onodera, S. Mizukami, M. Kato, T. Tano, H. Tomono, M. Yanagisawa, and K. Kameyama, IDW '09 (2009) FLX2-2.

[3] T. Sekitani, H. Nakajima, H. Maeda, T. Fukushima, T. Aida, K. Hata, and T. Someya, Nature Mater. 8 (2009) 494-499.

[4] V. Dua, S. P. Surwade, S. Ammu, S. R. Agnihotra, S. Jain, K. E. Roberts, S. Park, R. S. Ruoff, and S. K. Manohar, Angew. Chem. Int. Ed. 49 (2010) 2154-2157.

[5] J. Jang, J. Ha, and J. Cho, Adv. Mater. 19 (2007) 1772-1775.

[6] M. Zirkl, A. Sawatdee, U. Helbig, M. Krause, G. Scheipl, E. Kraker, P. A. Ersman , D. Nilsson, D. Platt, P. Bodo, S. Bauer, G. Domann, and B. Stadlober, Adv. Mater. 23 (2011) 2069-2074.

[7] T. N. Ng, B. Russo, B. Krusor, R. Kist, and A. C. Arias, Org. Electron. 12 (2011) 2012-2018.

[8] M. Allen, C. Lee, B. Ahn, T. Kololuoma, K. Shin, and S. Ko, Microelectron. Eng. 88 (2011) $3293-3299$.

[9] H. Kang, H. Park, Y. Park, M. Jung, B. C. Kim, G. Wallace, and G. Cho, Sci. Rep. 4 (2014) 5387.

[10]K. Fukuda, T. Sekine, Y. Kobayashi, Y. Takeda, M. Shimizu, N. Yamashita, D. Kumaki, M. Itoh, M. Nagaoka, T. Toda, S. Saito, M. Kurihara, M. Sakamoto, and S. Tokito, Org. Electron. 13 (2012) 3296-3301. 
[11]J. Perelaer, A. W. M. de Laat, C. E. Hendriks, and U. S. Schubert, J. Mater. Chem. 18 (2008) 3209-3215.

[12] G. Harsanyi, G. Inzelt, Microelectron. Reliab. 41 (2001) 229-237.

[13]K. Woo, C. Bae, Y. Jeong, D. Kim, and J. Moon, J. Mater. Chem. 20 (2010) 3877-3882.

[14]S. Jeong, H. C. Song, W. W. Lee, H. J. Suk, S. S. Lee, T. Ahn, J.-W. Ka, Y. Choi, M. Hye Yib, and B.-H. Ryu, J. Mater. Chem. 21 (2011) 10619-10622.

[15]H.-S. Kim, S. R. Dhage, D.-E. Shim, and H. T. Hahn, Appl. Phys. A 97 (2009) 791-798.

[16] W.-S. Han, J.-M. Hong, H.-S. Kim, and Y.-W. Song, Nanotechnology 22 (2011) 395705.

[17]B.-Y. Wang, T.-H. Yoo, Y.-W. Song, D.-S. Lim, and Y.-J. Oh, ACS Appl. Mater. Interfaces 5 (2013) 4113-4119.

[18]R. Dharmadasa, M. Jha, D. A. Amos, and T. Druffel, Appl. Mater. Interfaces 5 (2013) 13227-13224.

[19]L.-L. Chua, J. Zaumseil, J.-F. Chang, E. C. W. Ou, P. K. H. Ho, H. Sirringhaus, and R. H. Friend, Nature 434 (2005) 194.

[20]D. J. Gundlach, J. E. Royer, S. K. Park, S. Subramanian, O. D. Jurchescu, B. H. Hamadani, A. J. Moad, R. J. Kline, L. C. Teague, O. Kirillov, C. A. Richter, J. G. Kushmerick, L. J. Richter, S. R. Parkin, T. N. Jackson, and J. E. Anthony, Nature Mater. 7 (2008) 216-221.

[21]J. Zaumseil, K. W. Baldwin, and J. A. Rogers, J. Appl. Phys. 93 (2003) 6117-6124.

[22]X. Sun, Y. Liu, C. Di, Y. Wen, Y. Guo, L. Zhang, Y. Zhao, and G. Yu, Adv. Mater. 23 (2011) 1009-1014. 
[23]M. Xu, M. Nakamura, M. Sakai, and K. Kudo, Adv. Mater. 19 (2007) 371-375. 


\section{Figures captions}

Fig. 1. A schematic diagram of the irradiation system with Xenon (Xe) flash lamps.

Fig. 2. (a) The device structure of pentacene TFT and the molecular structure for pentacene and

PFBT. Microscopic photographs of (b) pentacene TFT and (c) channel region.

Fig. 3. (a) Relationship between the resistivity of $\mathrm{Cu}$ nanoparticle layer and radiant energy density

from the flash lamp. (b) SEM image of Cu nanoparticle layer before photonic sintering. (c) SEM image of $\mathrm{Cu}$ nanoparticle layer after photonic sintering with $5.9 \mathrm{~J} / \mathrm{cm}^{2}$ energy density.

Fig. 4. The cross-sectional profile and schematic image of $\mathrm{Cu}$ nanoparticle layer on a $\mathrm{BCB}$ polymer dielectric underlayer after photonic sintering with energy densities of (a) $4.4 \mathrm{~J} / \mathrm{cm}^{2}$ and (b) 5.9 $\mathrm{J} / \mathrm{cm}^{2}$

Fig. 5. (a) Transfer and (b) output characteristics of pentacene TFT with printed $\mathrm{Cu}$ nanoparticle as $\mathrm{S} / \mathrm{D}$ electrode.

Fig. 6. Photoelectron spectroscopy measurements in air for printed $\mathrm{Cu}$ electrodes with and without PFBT treatment. 
Fig. 7. (a) Total resistance in the channel as a function of channel length and (b) Dependence of contact resistance on gate voltage for a pentacene TFT with printed $\mathrm{Cu}$ electrodes treated with PFBT.

Fig. 8. AFM images at the edge of $\mathrm{Cu}$ electrode (a) before photonic sintering, (b) after pentacene deposition on the surface without photonic sintering, (c) after photonic sintering, and (d) after pentacene deposition on the photonically sintered surface. 


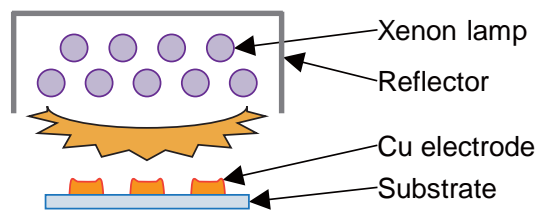

Figure 1 Norita et al. 


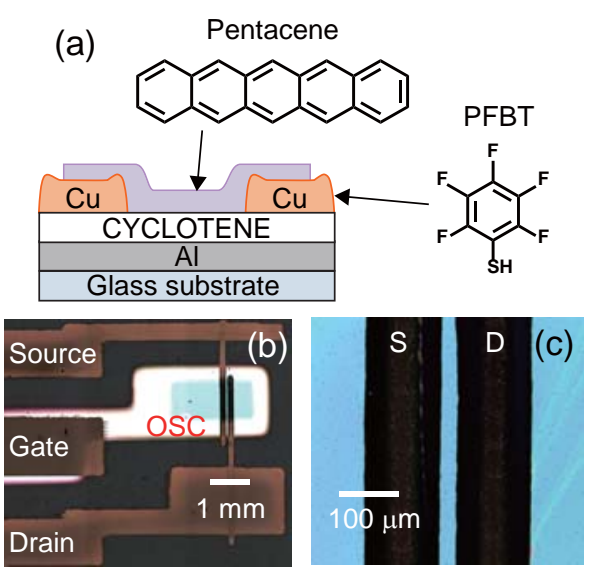

Figure 2 Norita et al. 


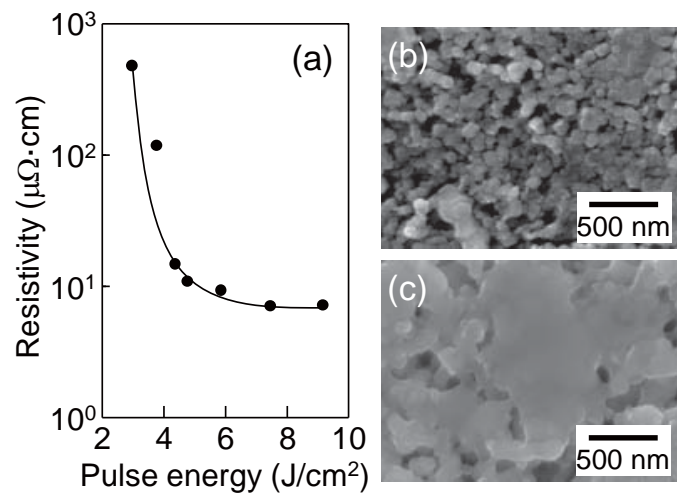

Figure 3 Norita et al. 


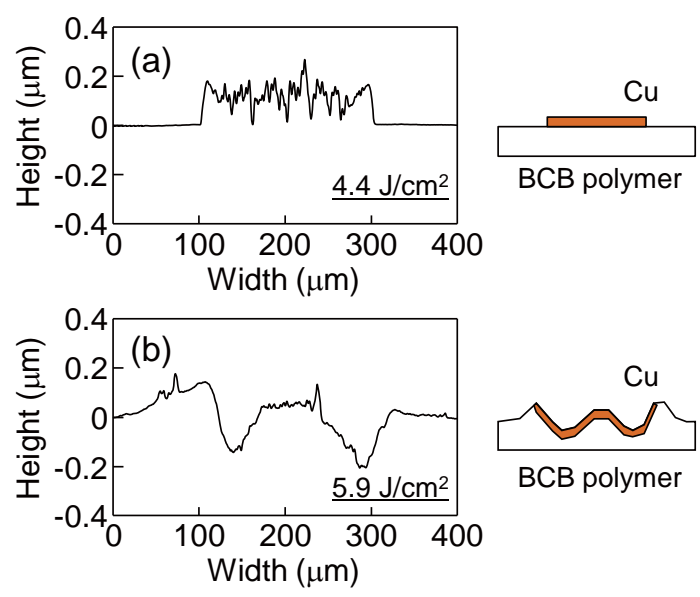

Figure 4 Norita et al. 

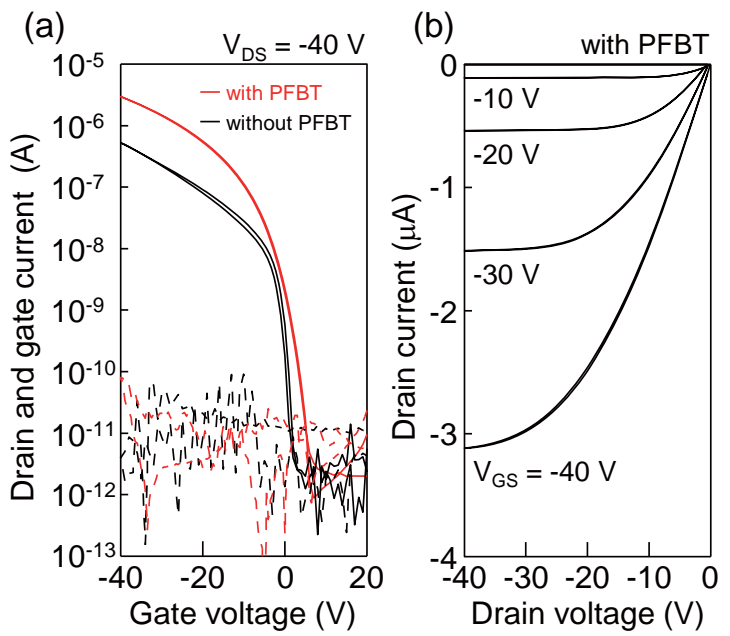

Figure 5 Norita et al. 


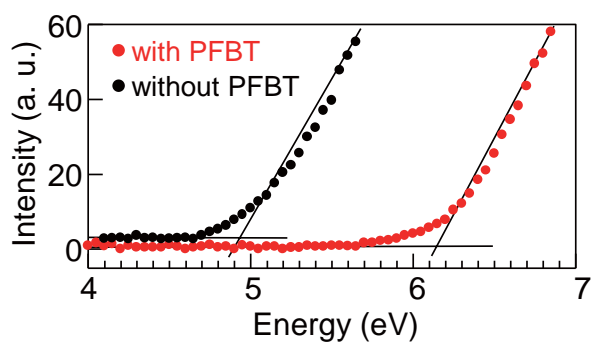

Figure 6 Norita et al. 

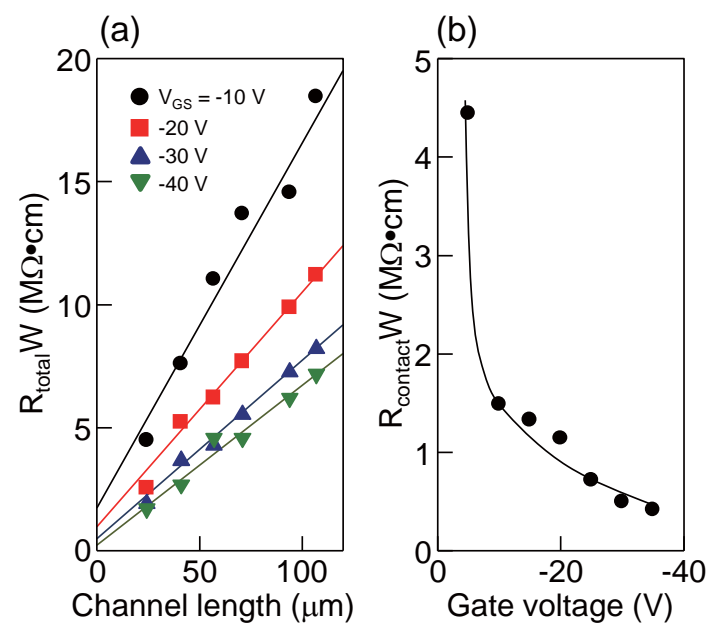

Figure 7 Norita et al. 


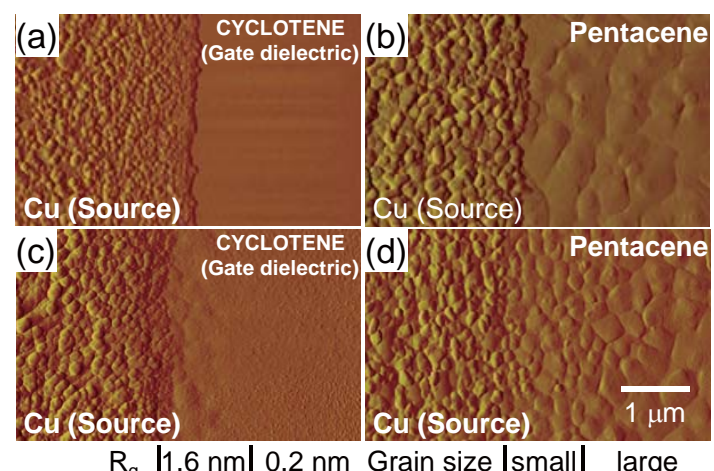

Figure 8 Norita et al. 
